\title{
Light and electron microscopic studies on lung and myocardium of the mice fetuses maternally treated with monosodium glutamate and role of vitamin $E$ against toxicity
}

\author{
Aleya Ahmed Sakr \\ Department of Zoology, Faculty of Science, Ain Shams University
}

\begin{abstract}
The lung and myocardium of fetal mice were used in the present investigation as a model to evaluate the possible effect of monosodium glutamate as one of the flavor food additives. Vitamin E was also used as one of the antioxidant agents against wide range of cellular damage.

In this study, light microscopic examination revealed that monosodium glutamate caused narrowing of the lung airways, thickening of the alveolar walls and collapsing of the alveoli. The cardiac muscles showed severe atrophy and abundance of blood capillaries. The ultrastructure studies revealed remarkable damage of type I and type II pneumocytes as well as the endothelial cells. Severely degenerated alveolar areas and accumulated collagen bundles were detected in the alveolar wall. The ultrastructure of the fetal myocardium revealed severe atrophy and destruction of cardiac muscle fibers. Some of these fibers tend to accumulate around blood capillaries which lined by attenuated endothelium. Numerous fibroblasts, fibrillary network, collagen and macrophages were obvious in the myocardium of these fetuses.

Light and ultrastructural results showed that the treatment of pregnant mice with vitamin $\mathrm{E}$ leads to apparent repair of the lung tissues that may suggest a remarkable efficacy of this vitamin against pulmonary damage. On the other hand, the protective effect of vitamin $\mathrm{E}$ on the fetal myocardium was weak.
\end{abstract}

\section{Introduction}

Monosodium glutamate (MSG) is a wellknown flavor enhancer used in both Western and Eastern cuisines. It is responsible for the delicious taste, and it is incorporated into a large number of solid and liquid foods. Experimental studies have established that the presence of added MSG in foods influences palatability and preference (Bellisle, 1998).

Although MSG as a food additive was reported to have toxic effects in different organs of human and animals, adults and fetuses (Yu et al., 1997; Horio, 2000 and Schoelch et al., 2002), MSG remains one of the most studied materials in the world food supply.

Glutamate receptors are present in the central nervous system as the major mediators of excitatory neurotransmission and excitotoxicty. Neural injury associated with trauma, stroke, epilepsy, and many neurodegenerative diseases such as Alzheimer's, Huntigton's and Parkinson's diseases and amyotrophic lateral sclerosis may be mediated by excessive activation of glutamate receptors (Gill et al., 2000). In addition, neonatal MSG treatment is known to cause neuronal cell death, dendritic hypertrophy (Gonzalez-Burgos et al., 2001), arcuate nucleus damage and energy balance alteration (Schoelch et al., 2002). Moreover, MSG has been shown to alter several neuroendocrine functions in neonatally treated rats. It causes marked reduction in pituitary, thyroid, adrenal, gonadal and prostate weights (Dolnikoff et al., 1988; Tokarev and Jezova, 2000).

Less is known about glutamate receptors outside the central nervous system. Recent observations suggest that several subtypes of glutamate receptors are widely distributed in peripheral tissues. 
Using immunochemcial and molecular techniques, the presence of glutamate receptors subtypes was demonstrated in the rat and monkey heart, with preferential distribution within the conducting system. The receptors are also present in the kidney, liver, lung, spleen and testis (Gill et al., 2000). Therefore, these tissues considered as potential target / effector sites. It would appear that the fate of ingested processed glutamic acid may be to move to any glutamate receptors available to it, and to create an adverse or toxic reaction if any one of those peripheral glutamate receptors is weak.

Little is known about the effect of MSG on the lung and many questions have been raised about MSG and provocation of asthma. It has been observed that MSG induces signs and symptoms of asthma. Stevenson (2000) reported that MSG induced asthma attacks in a number of asthmatic patients and in such patients lung function was disturbed. Similarly, Allen et al. (1987) and Woessner et al. (1999) reported cases of asthma following MSG ingestion through food and they found that the reaction to MSG is dose dependent and may be delayed up to 12 hours, making recognition difficult for both patient and physician.

Relationship between taste stimuli, including monosodium glutamate, and heart rate was studied by few scientists. Horio (2000) reported increased heart rate in healthy human following different concentrations of taste stimuli. Also, Tokarev and Jezova (2000) obtained the same results in rats neonatally treated with monosodium glutamate.

Monosodium glutamate was shown to penetrate placental barrier and to distribute to embryonic tissues using $(3 \mathrm{H})$ glutamic acid as a tracer (Yu et al., 1997). So, various developmental changes in the animals offspring were observed following MSG treatment. Frieder and Grimm (1984) and $\mathrm{Yu}$ et al. (1997) reported Juvenile obesity, reduced general activity, and learning disability in rat and mouse dams that received MSG through their mothers during pregnancy.
The human body possesses a number of mechanisms to deal with the potentially damaging effects of free radicals and their metabolic products. Nutrients also contribute to defense against oxidative stress and cellular damage. Examples include the sulfhydryl containing amino acids, the minerals, selenium, zinc, copper, and the vitamins riboflavin and tocopherol (vitamin E) (Oski, 1980). Vitamin E (vit E) is the oldest recognized biologic antioxidant and the studies describing its therapeutic benefits in infants can be classified into three categories. In the first, vit $\mathrm{E}$ has been used to correct a deficiency state and its associated pathologic abnormalities such as hemolytic anemia of low-birth-weight infants (Natta et al., 1980). A second category in which vit $\mathrm{E}$ is employed to counter the effects of prooxidant assault. For example, vit $\mathrm{E}$ has been used to reduce the severity of bronchopulmonary dysplasia in infants exposed to prolonged oxygen administration in the treatment of the respiratory-distress syndrome. It has also been employed to counter the cardiotoxic effects of some chemotherapeutic agents (Oski, 1980). The third category in which pharmacological doses of vit $\mathrm{E}$ have been employed, includes situations in which the antioxidant has been used to compensate for a preexisting defect in the body's defense against free radicals. Among the examples are hereditary hemolytic anemias due to deficiencies in glutathione synthetase and glucose-6-phosphate dehydrogenase (McCord and Fridovich, 1978).

The aim of this study was to determine the ultrastructural changes in lung and myocardium of mice fetuses maternally-treated with MSG and the protective role of vit $\mathrm{E}$ against pulmonary and cardiac toxicity induced by MSG.

\section{Materials and methods}

CD-1 mice weighing 30-40 $\mathrm{g}$ were used in this study. The animals were maintained on a standard diet and had water ad libitum. Adult females were caged with adult males at a ratio of $2: 1$. The day on which sperms were found in the vaginal 


\section{Aleya Ahmed Sakr}

smear was considered as day one of gestation. Pregnant females were divided into three groups. The first group served as control and received daily oral dose of 0.5 $\mathrm{ml}$ of distilled water from the $1^{\text {st }}$ to the $18^{\text {th }}$ day of gestation. The second group received MSG in daily oral dose of $2 \mathrm{mg} / \mathrm{g}$ body weight ( Mistlberger and Antle, 1999) from the $1^{\text {st }}$ to the $18^{\text {th }}$ day of gestation. The third group received vit $\mathrm{E}$ in daily oral dose 2.6 $\mathrm{mg}$ and the same MSG dose for the same period.

On the $19^{\text {th }}$ day of gestation, all females were sacrificed and their living fetuses were taken. Samples of lung and myocardium (left ventricle) were removed from fetuses, and fixed in $2 \%$ cold glutaraldehyde in $0.1 \mathrm{M}$ phosphate buffer at $\mathrm{pH} 7.2$ for 4 hours. Fixed specimens were washed in three changes of $0.1 \mathrm{M}$ phosphate buffer for one hour and then post fixed in $2 \%$ osmium tetroxide. The double-fixed tissues were washed in three changes of 0.1 M phosphate buffer followed by a short rinse in distilled water and dehydrated in ascending grades of ethanol, then acetone and embedded in epon 812. Semithin sections were stained with toluidine blue. Ultrathin sections were stained with uranyl acetate and lead citrate. For light microscopy, samples of lung and myocardium were fixed in bouin and the sections were stained with hematoxylin-eosin.

\section{Results}

Light and electron microscopic examination

\section{Control lung}

Figure (1) represents the lung of the control mouse fetus as seen by light microscope. The air spaces are wide and the alveolar wall consists of thin epithelium. The blood capillaries are lined by flat endothelial cells and capillary network lies between the walls of the alveoli.

Examination of the fetal lung with the electron microscope revealed that the alveolar surface is lined by epithelial cells which are of two types, type I pneumocytes (squamous alveolar cells) and type II pneumocytes (great alveolar cells). Type I pneumocytes are squamous cells which extend over the basal lamina as a thin sheet and join other epithelial cells making up the continuous alveolar lining. Their cytoplasm is deficient in the cytoplasmic organells and they possess large nuclei. Type II Pneumocytes are secretory cells and their primary role is synthesizing and secreting surfactant. They are large cells, have surface microvilli and their cytoplasm contains free ribosomes and few lamellar bodies(surfactant bodies) which contain few lamellar contents (Fig. 2). Sometimes the cells appear nearly devoid of these lamellar bodies. The alveolar macrophage can be found within the surface lining layer as well as in the supporting tissue of the alveolar septa (Fig. 2). Their cytoplasm contains numerous vacuoles, electron dense inclusions and ingested lamellar bodies.

The air (gas exchange) barrier between blood and alveolar air is extremely thin and consists of thin cytoplasm of a type I pneumocyte, fused basement membrane (epithelial and endothelial basement membranes) and cytoplasm of the capillary endothelial cells (Fig. 3). The bronchioles are lined by two major cell types, ciliated and nonciliated. The nonciliated cells are tall, and protrude into the bronchiolar lumen (Fig. 4).

\section{Lung of MSG maternally-treated fetuses}

As seen in light microscopy, lung of MSG maternally-treated fetuses showed certain changes as compared with the control. The alveolar walls were widened and consequently the alveoli were compressed (Fig. 5). The epithelial cells which line the bronchioles were hypertrophied, might be distended with mucus, so the lumen of the bronchioles became narrow (Fig.6). Few fibroblasts were sometimes seen inside the lumen of the bronchioles.

Electron micrographs of the lung of these fetuses revealed that nearly all the pneumocytes of type I were deformed and they exhibited different signs of damage. Some cells showed signs of necrosis and fragmented parts of these cells were seen in the alveolar spaces (Fig. 7). In few other cells, the cellular membrane as well as the thin cytoplasmic extensions of the cells 
were mostly destructed (Fig. 8). In addition, few cells were hypertrophied (Fig. 9) while others lost their squamous shape, became cuboidal and were found bulged into the alveolar space (Fig. 10).

Type II pneumocytes showed partial loss of their cytoplasmic organelles and contained few lamellar contents as in the control lung (Fig. 10). Desquamated type II pneumocytes were observed in the air spaces. However, moderate increase in their number was detected.

An obvious damage was observed in the capillary endothelial cells of the lung of these fetuses. The cells showed signs of necrosis, irregularity, and their cytoplasm contained vacuoles and dense granules (Figs.7-11) and most of them had hyperchromatic nuclei. The thin cytoplasm of these endothelial cells lining blood capillaries was attenuated and atrophied (Fig.7). However, sometimes showed thickening and irregularity (Fig. 8).

The alveolar wall revealed focal areas of cell necrosis. In such areas, the cells were completely destructed and an extraordinary increase in the collagen was observed (Fig.12) where accumulated collagen fibers were deposited in the interstitium. Generally, there was marked increase in the amount of collagen elsewhere in the alveolar wall (Figs. 9-12). On the other hand, numerous vacuoles and lipid droplets were seen in the interstitium and inside the cells. (Figs. 7, 9 and 12). Moreover, thin elongated fibroblasts and cell debris were sometimes seen in the alveolar spaces (Fig. 13).

\section{Lung of fetuses maternally-treated with vit $E$ and $M S G$}

Light microscopic preparation showed that the alveoli were slightly expanded as compared with non vitamin $\mathrm{E}$ treated fetuses. The alveolar walls possessed moderately thin walls except for a few foci where the alveolar walls were still thickened (Fig. 14). The bronchiolar epithelium showed no observable change in the light microscopic preparations.

At the ultrastruscte level, most of the alveolar septal cells showed nearly normal structure (Fig. 15) and the severely affected cells which were seen in MSG maternallytreated fetuses were hardly seen in vit $\mathrm{E}$ protected animals. However, electronlucent membrane-bounded vacuoles were seen in some cells and in few other cells, mitochondria were swollen with apparent loss of cristae (Fig. 16). Nuclei of these affected cells were found irregular possessing condensed chromatin mainly against the nuclear membrane.

In this group of fetuses, type I and II pneumocytes showed signs of repair and most of the cells regained nearly their normal appearance (Figs. 17 and 18). Moreover, an improvement of type II pneumocytes represented by mild increase in their dense lamellar contents was observed (Fig. 17). Lamellar bodies were sometimes seen in the lumen of the blood capillaries.

However, signs of injury were still represented in the capillary endothelial cells where some cells were enlarged and the lumen of the blood capillaries became narrow. Others were partly detached from the capillary wall and bulged into the lumen (Fig.17).

The number of macrophages increased in the lungs of these fetuses and they were seen either in the alveolar spaces (Fig. 18) or inside the blood capillaries (Fig. 15) and they contained phagocytic vacuoles (Figs.15 and 18). The interstitium was patchy infilterated with neutrophils (Fig. 15) and collections of collagen were still observed (Fig. 16).

The cytoplasm of the bronchiolar epithelial cells contained numerous vacuoles which accumulated at the supranuclear region of the cells. In addition, the cells had lost their apical cilia (Fig. 19)

\section{Control myocardium:}

In the light microscopic preparation, the fetal myocardium is composed of cardiac muscle fibers which consist of individual cells, cardiocytes, containing one or two spindle shaped nuclei. Moderate number of blood capillaries are scattered through the myocardium (Fig. 20).

At the ultrastructure level, the cardiocytes contain parallel myofilament bundles, oval nuclei and numerous 


\section{Aleya Ahmed Sakr}

mitochondria which are evenly distributed, dividing cardiac muscle cells into apparent myofibrils (Fig.21).

\section{Myocardium of fetuses maternally-treated with MSG}

At the light microscopic level the cardiac muscle fibers of MSG maternallytreated fetuses showed severe atrophy and irregularity. Abundance of blood capillaries was the characteristic feature of the myocardium of these fetuses (Fig. 22).

Electron microscopic observations revealed that the cardiac muscle fibers suffered from varying degrees of degeneration, ranging from severe atrophy, loss of striations, loss of mitochondria to complete necrosis and fragmentation (Figs. 23-27). Generally, the muscle fibers were irregular, atrophied and they became widely separated by large spaces (Fig. 23). Fragmented fibers were observed at certain regions and these fibers were found accumulated specially around blood capillaries (Fig. 24).

Numerous elongated fibroblasts with poorly-defined cytoplasmic margins were scattered throughout the myocardial tissues. These cells send out a system of slender branching cell processes inbetween surrounding injured muscle fibers (Fig. 25). These fibroblasts with their processes were sometimes seen encircling groups of degenerated muscle fibers (Fig. 26).
The characteristic feature of the myocardium of these fetuses was the marked proliferation and abundance of blood capillaries which showed mild dilation (Fig. 24). The endothelium lining these blood capillaries was attenuated and atrophied and macrophages were sometimes seen inside the lumen of these capillaries (Fig. 24). Depositions of collagen were observed either inside the cardiac muscle fibers or outside it (Fig.27).

\section{Myocardium of fetuses maternally-treated with vit $E$ and $M S G$}

Light and electron microscopic examination of fetal myocardium showed that vit $\mathrm{E}$ failed to protect against MSG induced cardiotoxicity (Figs.28-31). Atrophied cardiac muscle fibers were still represented and the nuclei of cardiocytes became highly irregular (Fig. 29). The blood capillaries were abundant and their endothelial lining was still attenuated (Fig. 29). Numerous vacuoles of different shapes and sizes were seen in the cardiac muscle fibers (Fig. 30). Electron-lucent structures with flocculent and particulate contents were also observed in the muscle fibers (Fig. 31). As in MSG non vit E maternallytreated fetuses, the muscle fibers showed loss of striations as well as loss of mitochondria (Figs. 30 and 31). On the other hand, the amount of fibroblasts decreased in the myocardium of this group of fetuses. 


\section{Light and electron microscopic studies on lung........}
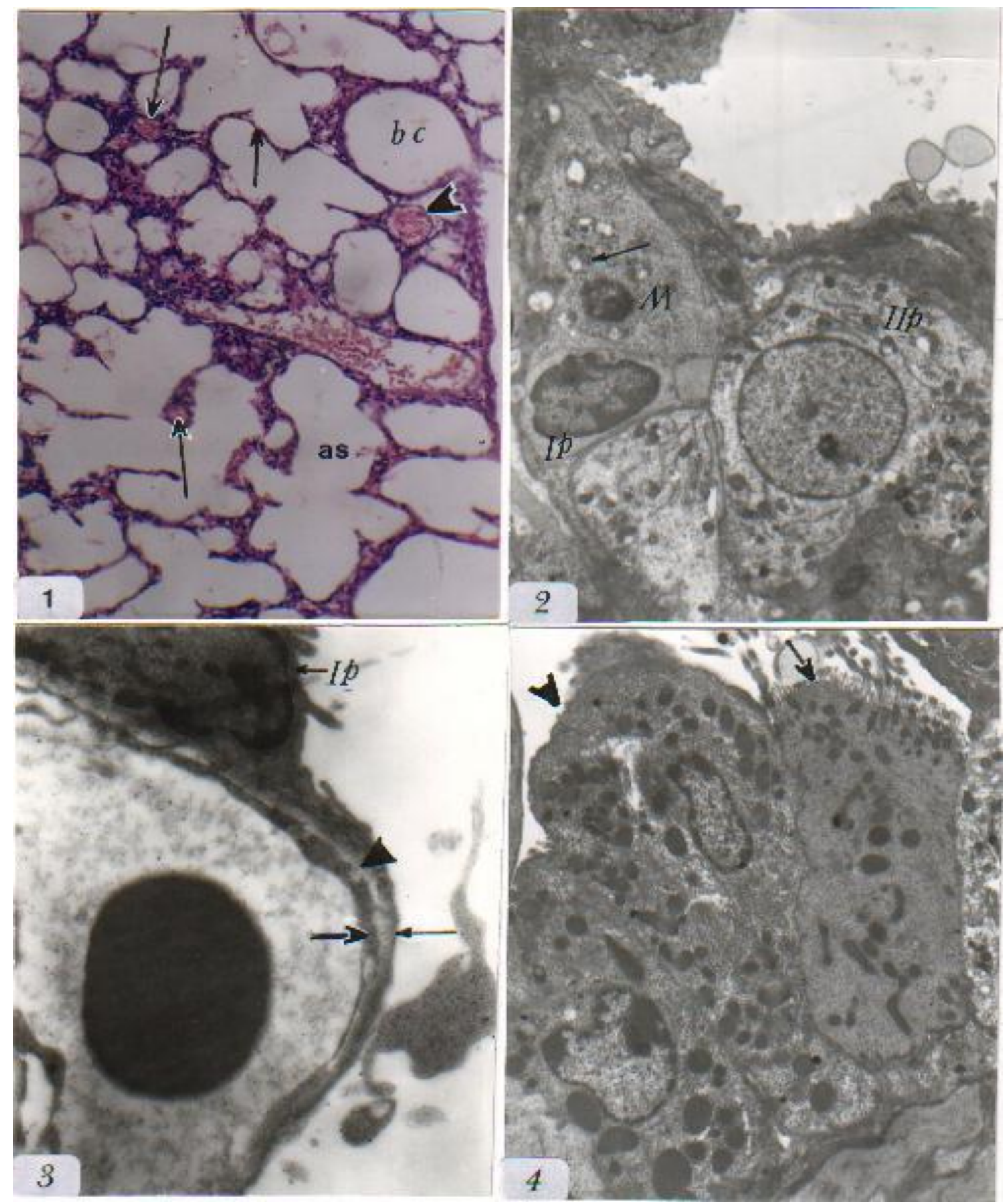

Fig. 1: Light microscopic photograph of control lung tissue revealing alveolar sacs (as), interalveolar septa (short arrow), branches of pulmonary arteriole (arrow head) and bronchioles (br). Blood capillaries lie between the walls of the alveoli (long arrows). (H\&E, X 100)

Figures 2-4 : Ultrastructure of control lung tissue

Fig. 2: An alveolar wall containing type I pneumocyte (IP), type II pneumocyte (IIP) and macrophage (M) containing ingested lamellar bodies (arrow). X 4500

Fig. 3: The gas exchange barrier between alveolar epithelium (thin arrow), basement lamina (arrow head), and the capillary endothelium (thick arrow). Type I pneumocyte is also seen (IP). X 9000

Fig. 4: Bronchiolar epithelium of a control fetus consisting of ciliated (arrow) and non ciliated cells (arrowhead). X 6000 

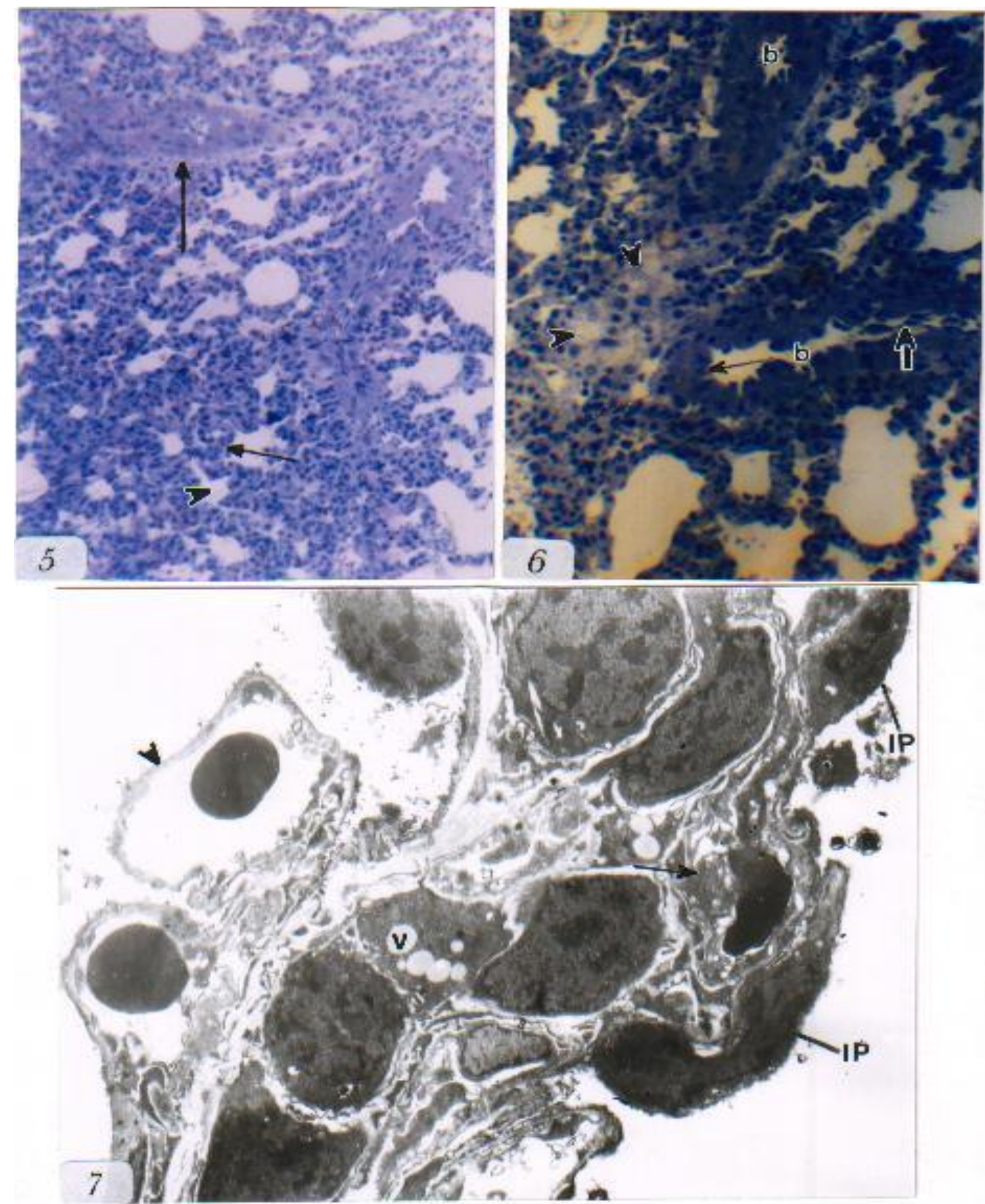

Figures 5-6: Light microscopic photographs of the lung tissue of MSG maternally- treated fetuses

Fig. 5: The alveolar walls (short arrow) are thickened with reduced alveolar space (arrow head) and the bronchiol (long arrow) exhibits narrow lumen. ( H\&E, X 100)

Fig. 6: High magnification showing the hypertrophied bronchiolar cells (thin arrow) and necrotic alveolar area (arrow heads) . The bronchiolar lumen (b) is narrow and contains some fibroblasts (thick arrow). (H\&E, X 400)

Figures 7-13: Ultrastructure of the lung tissues of MSG maternally-treated fetuses

Fig. 7: Alveolar wall with necrotic type I pneumocytes (IP), necrotic endothelial cell (arrow), attenuated endothelial lining (arrow head) and interstitium vacuoles (V). X 3000 


\section{Light and electron microscopic studies on lung........}
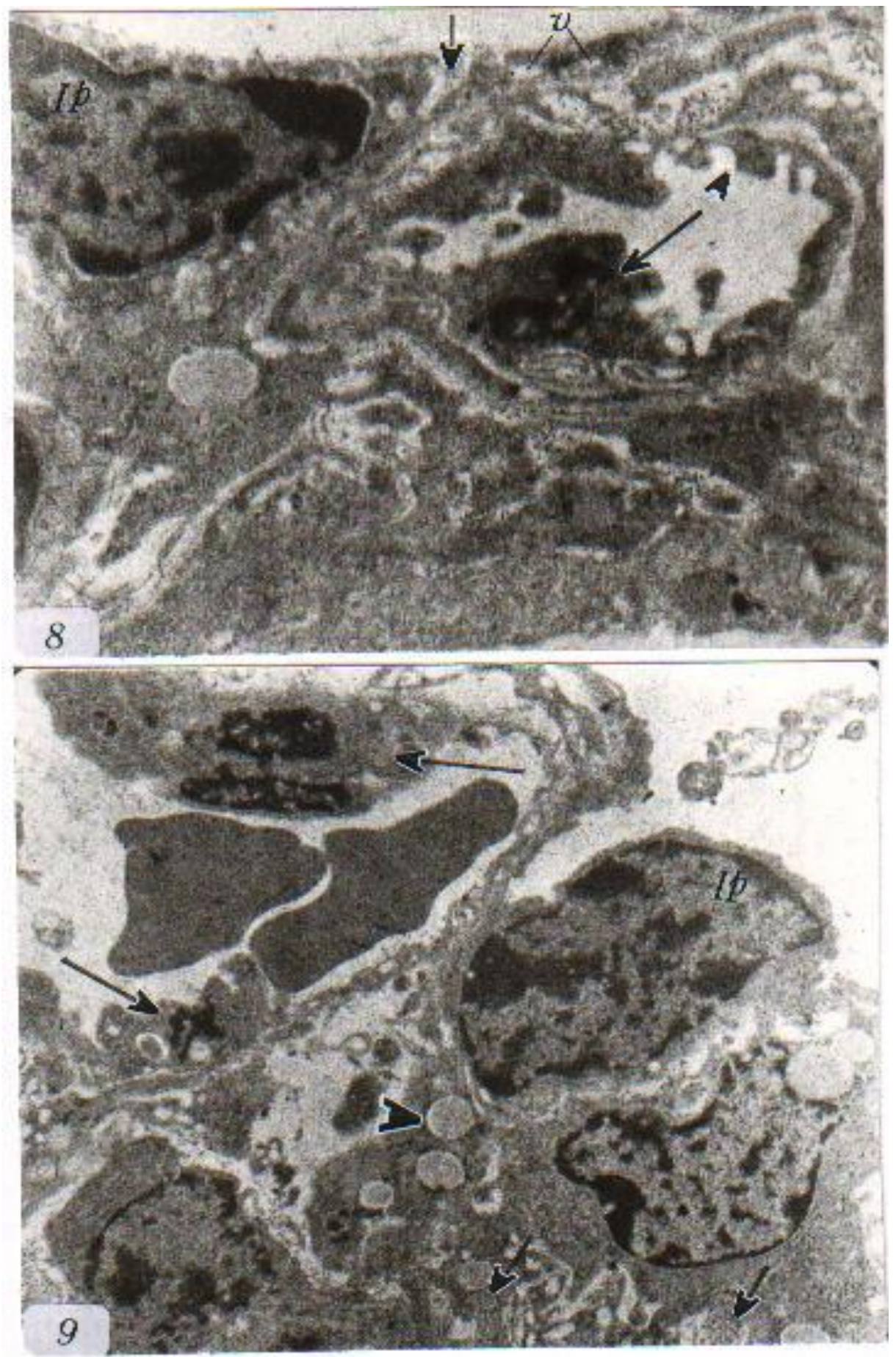

Fig. 8: Alveolar wall with injured type I pneumocyte (IP). The thin cytoplasmic extension contains vacuoles (V) and destructed regions (short arrow). The blood capillary has necrotic endothelial cell (long arrow) with thickened and irregular endothelial lining (arrow head). X 9000

Fig. 9: Alveolar wall with enlarged type I pneumocyte (IP), necrotic endo-thelial cells (arrows), lipid droplets (arrow head) and collag-en fibers (short arrows). X 4500 


\section{Aleya Ahmed Sakr}

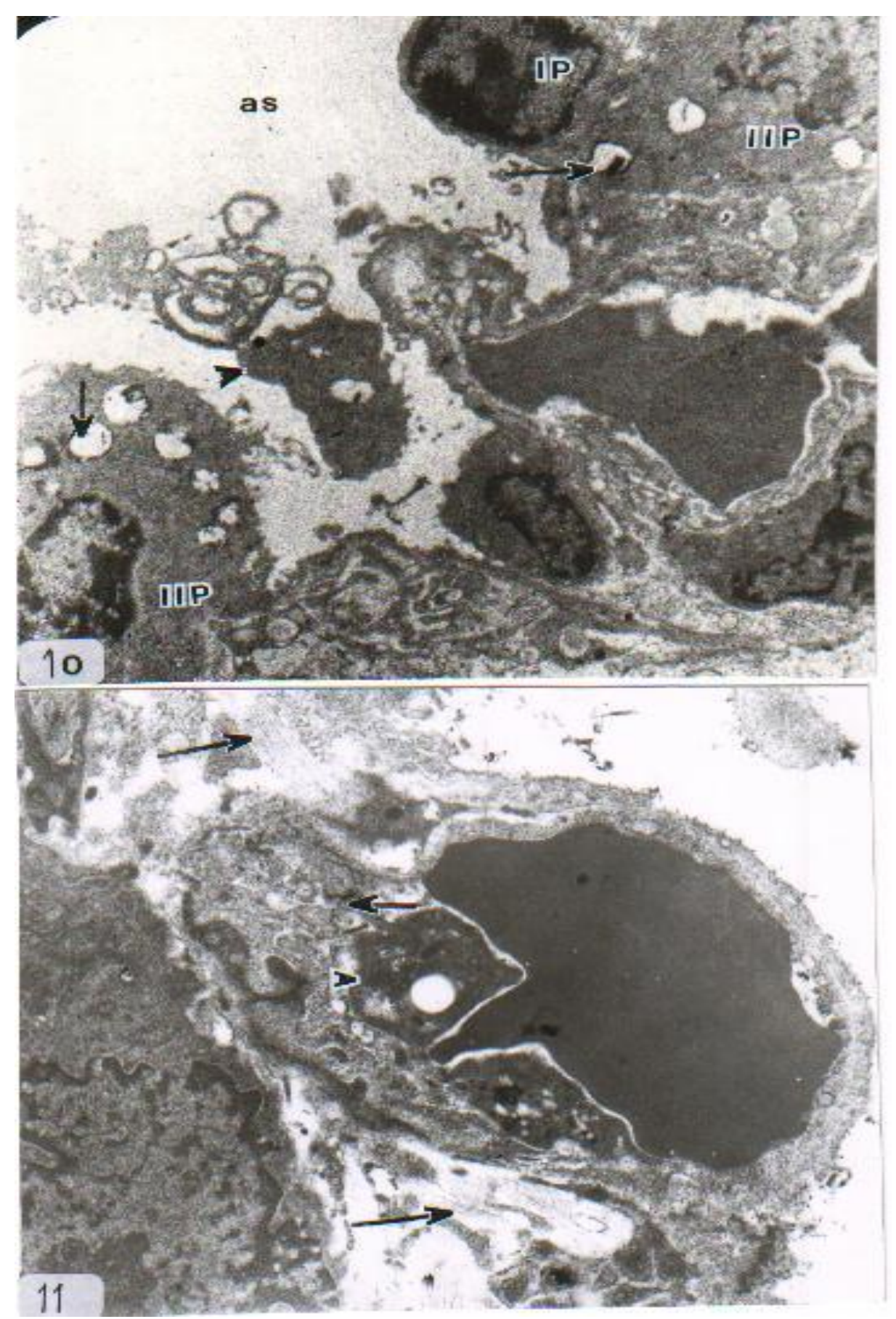

Fig. 10: Alveolar wall with cuboidal type I pneumocyte (IP) bulging into the alveolar space (as). The lamellar bodies of type II pneumocytes (IIP) contain few contents (arrows). Desquamated type II pneumocyte is observed in the alveolar space (arrow head). X 4500

Fig. 11: Blood capillary with necrotic endothelial cell (arrow head) and severely damaged endothelial lin-ing (short arrow). Patches of coll-agen fibers are seen in the interstitium (long arrows). X 7500 


\section{Light and electron microscopic studies on lung........}

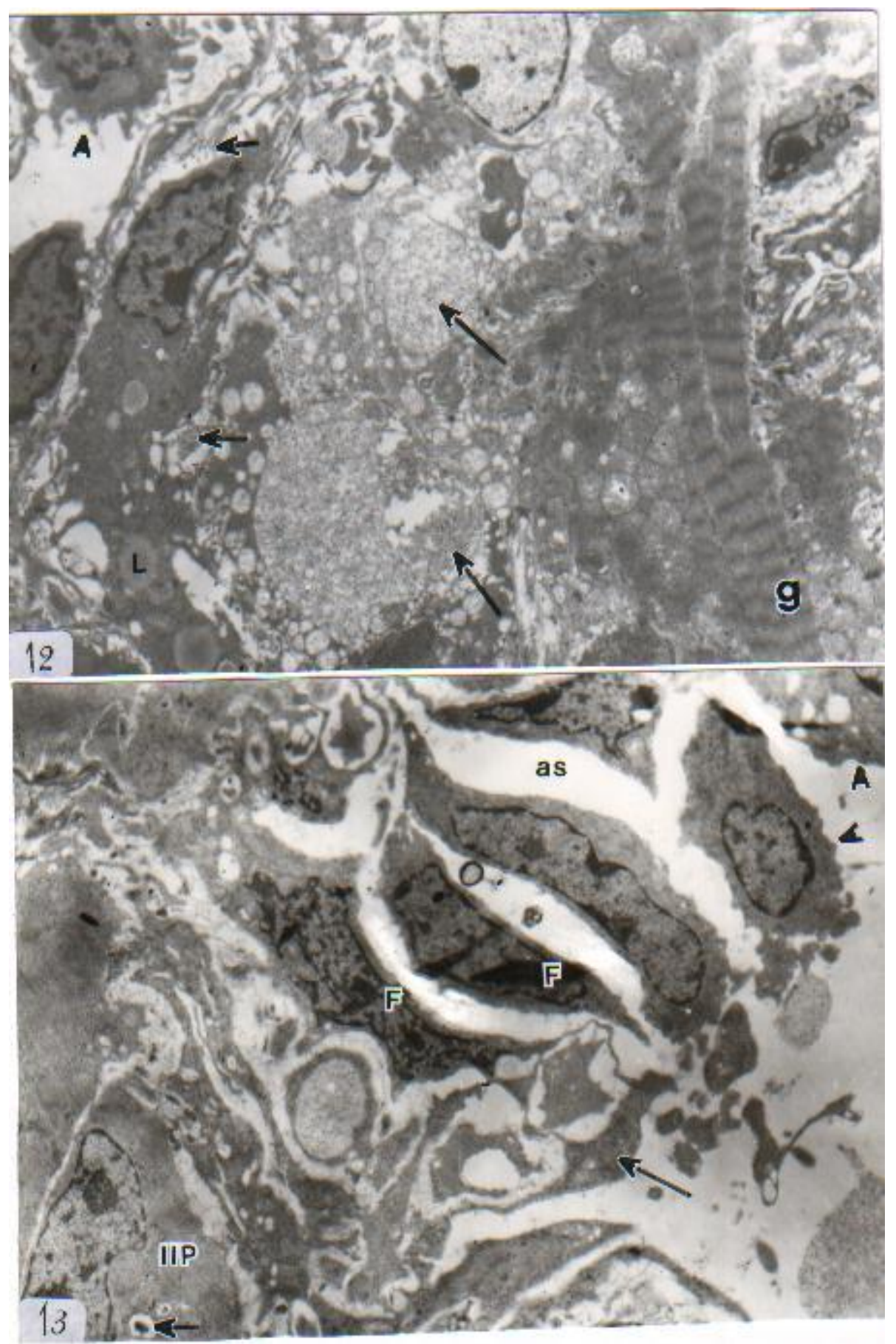

Fig. 12 : Severely damaged alveolar wall with necrotic cells (long arrows) containing numerous small vacuoles. Lipid droplets (L) are seen in the cytoplasm of the fibroblast and macrophage is seen in the alveolar space (arrowhead). Accumulated collagen bundles (g) and small depositions of collagen fibers are seen in the interstitium (short arrows). $\mathrm{X} 4500$

Fig. 13 : Alveolar space (as) containing thin elongated fibroblasts (F), some free cells (arrow heads), and destructed parts of the alveolar wall (long arrow). The cytoplasm of the type II pneumocyte (IIP) is nearly devoid of cytoplasmic organelles and contains few lamellar bodies (short arrow). X 4500 


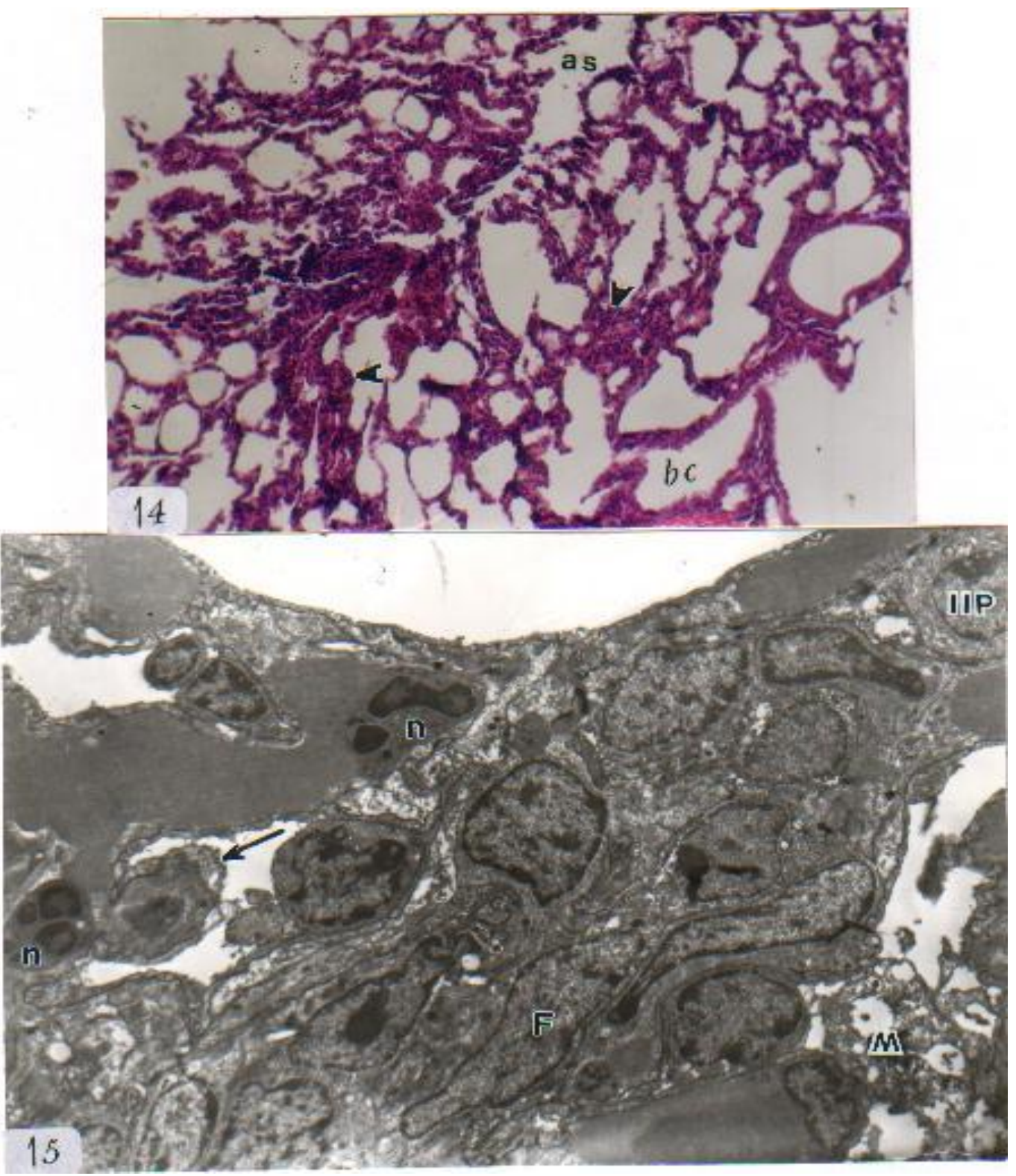

Fig. 14 : Light microscopic photograph of the lung tissue of vit E and MSG maternally-treated fetuses. The lung has moderately expanded alveolar sacs (as), wide bronch-iolar lumen (bc). Few thickened alveolar septa are still represented (arrow heads). (H\&E, X 100)

Figures 15-19: Ultrastructure of the lung tissue of vit $\mathrm{E}$ and MSG maternally-treated fetuses

Fig. 15 : Thickened alveolar wall showing intact cells, type II pneumocytes (IIP) and fibroblasts (F). Enlarged necrotic endothelial cell is bulging in the capillary lumen ( arrow) and macrophage (M) containing vacuoles is seen in the other capillary lumen. The interstitium is infilterated with neutrophils (n). X 3000 


\section{Light and electron microscopic studies on lung........}

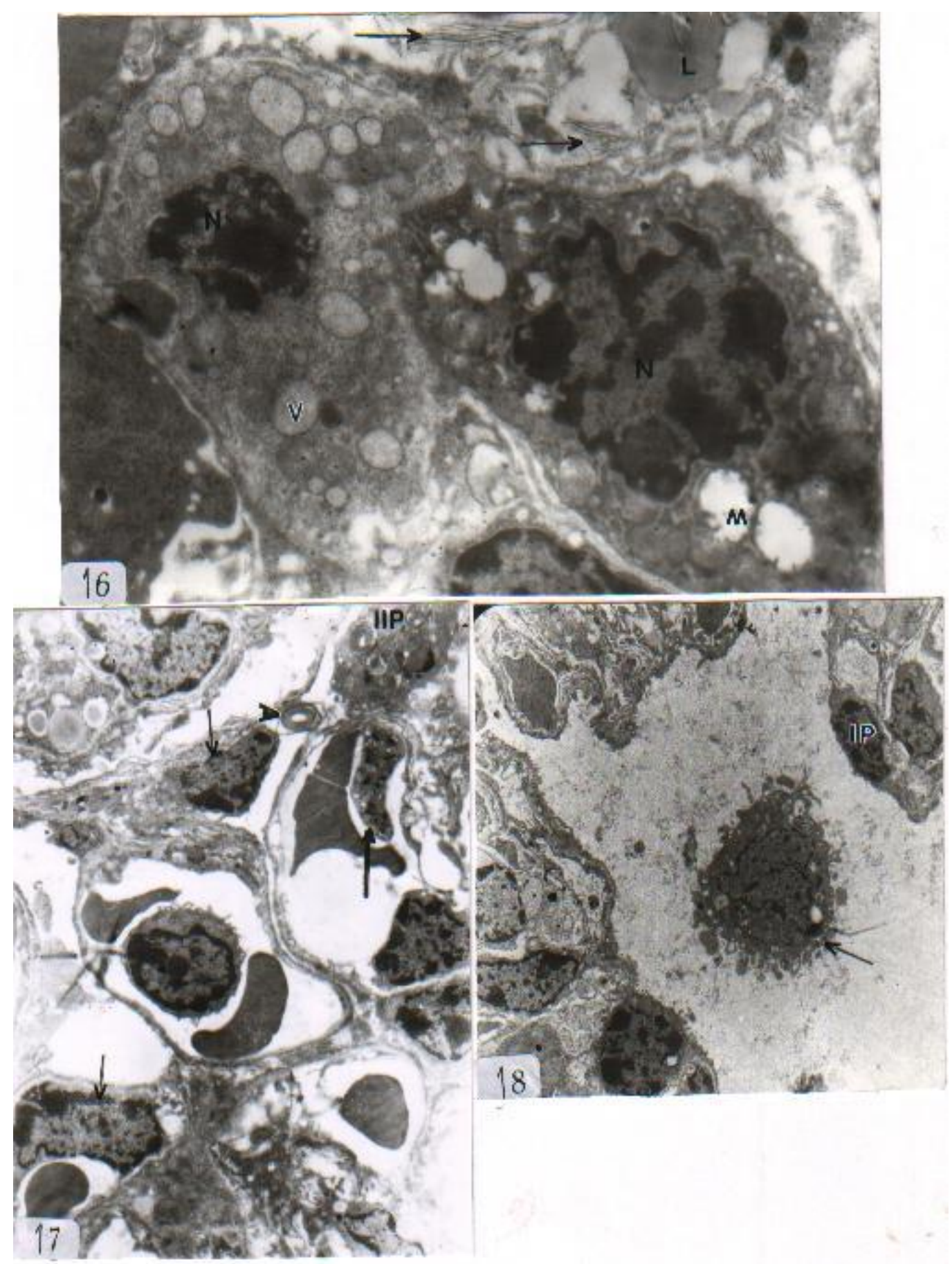

Fig. 16: Alveolar wall with two damaged cells. One of the cells (on the left) contains electronlucent membrane-bounded vacuoles (v) and pyknotic nucleus $(\mathrm{N})$. The other cell (on the right) contains vacuolated mitochondria and hyperchromatic nucleus $(\mathrm{N})$. The interstitium is infilterated with lipid droplets (L) and collagen fibers (arrows). X 7500

Fig. 17: Endothelial cells lining blood capillaries are enlarged and the lumen become narrow (thin arrows). Long and thin endothelial cell (thick arrow) is bulging into the capillary lumen. Type II pneumocyte (IIP) has well developed lamellar bodies. The latter is seen in the capillary lumen (arrow head). X 2500

Fig. 18: Alveolar space containing macrophage (arrow). Type I pneumocyte (IP) is seen. $X$ 2000 

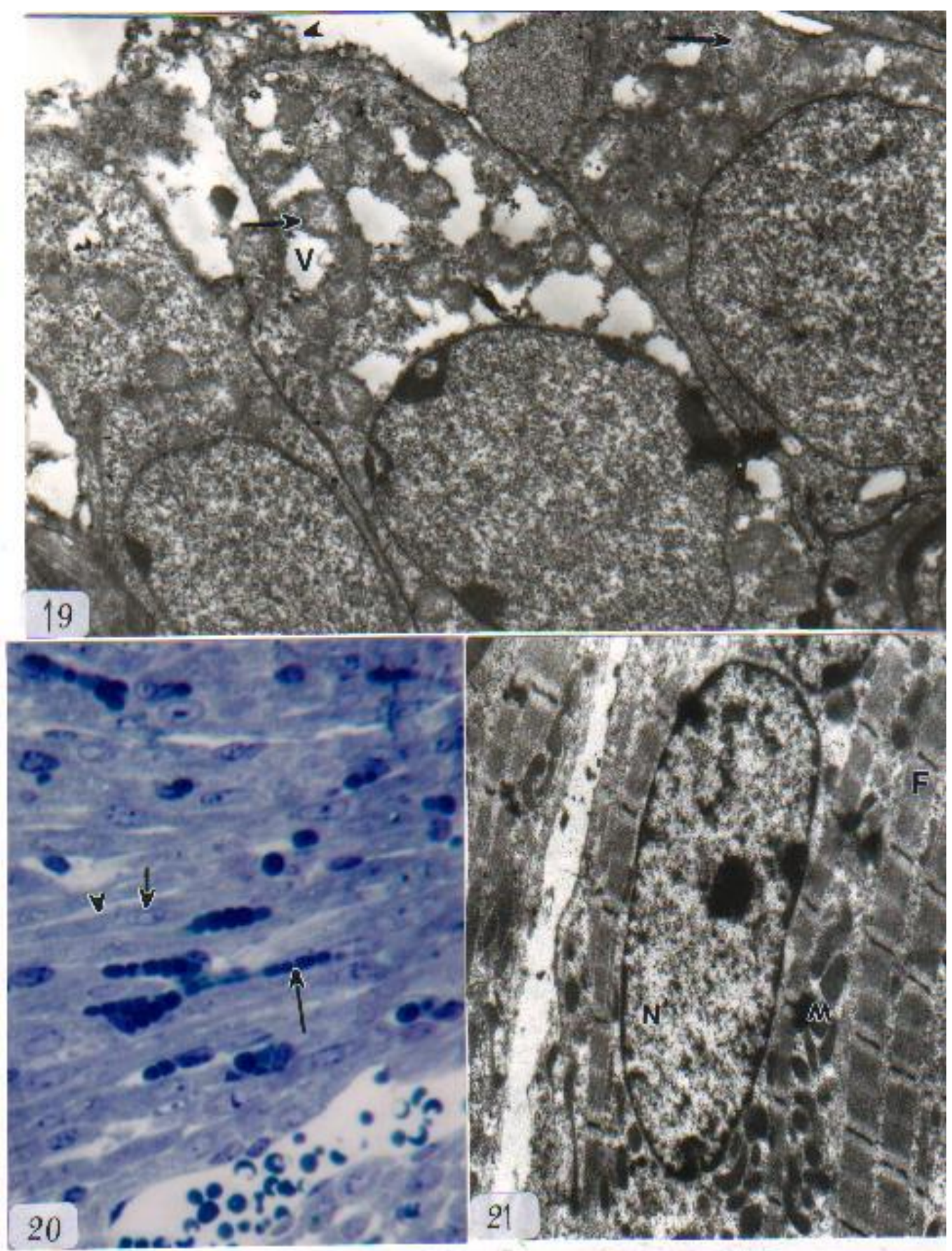

Fig. 19: The bronchiolar epithelial cells contain numerous vacuoles (V) and deformed mitochondria (arrows). The apical cilia of the cells are degenerated (arrow head). X 7500

Fig. 20: Light microscopic photograph of a control myocardium illustrating normal structure of cardiocytes (arrow head). The cells contain oval nuclei (short arrow) and blood capillaries (long arrow) are filled by blood cells. (H\&E, X 400)

Fig. 21: Electron micrograph of a control myocardium showing normal ultrastructure of cardiocyte. $\mathrm{N}=$ nucleus, $\mathrm{M}=$ mitochondria, $\mathrm{F}=$ myofilament. $\mathrm{X} 4500$ 


\section{Light and electron microscopic studies on lung........}
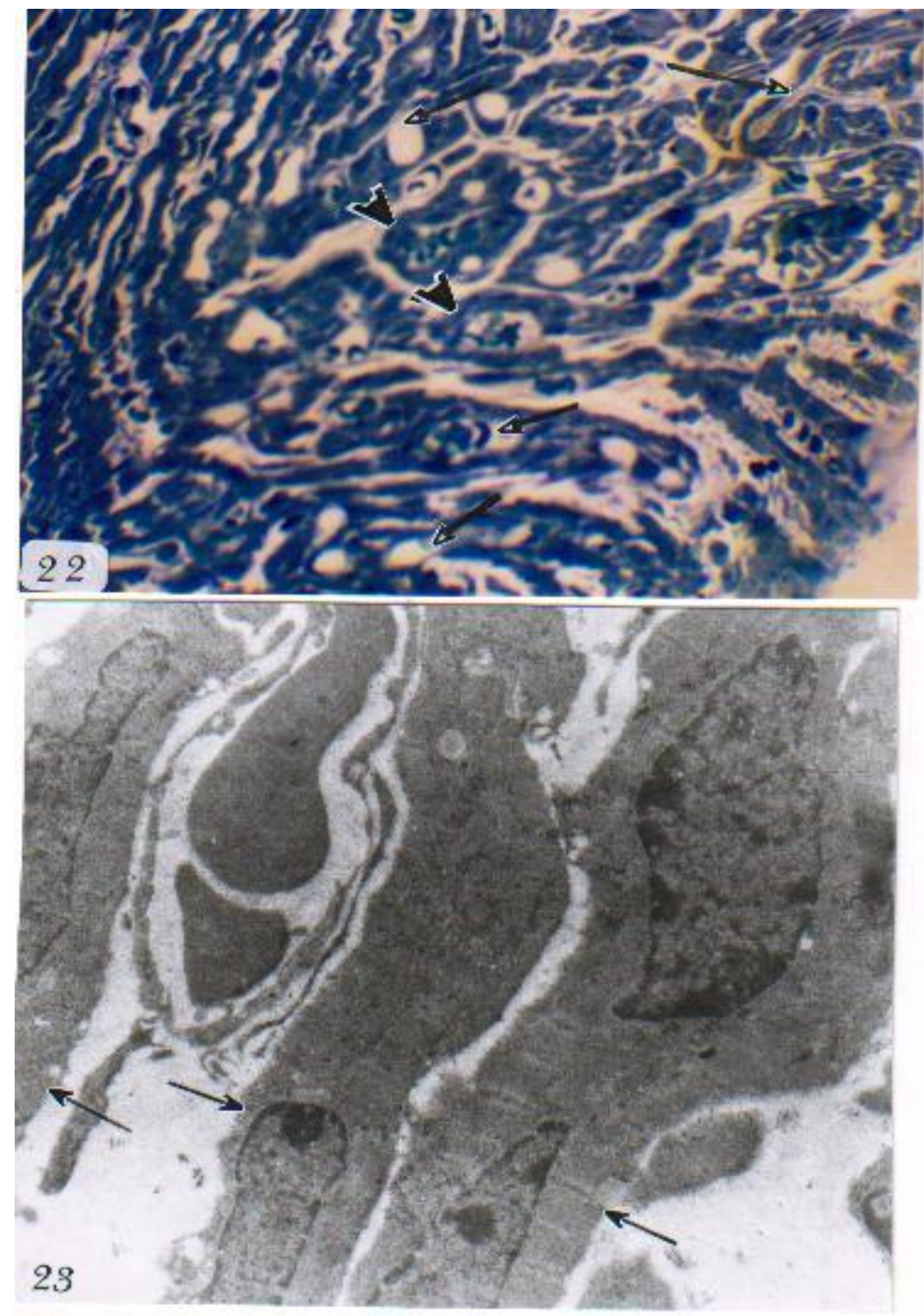

Fig. 22: Light microscopic photograph of the myocardium of MSG maternally-treated fetus showing severely atrophied and irregular muscle fibers, abundance of blood capillaries (short arrows), muscle fibers accumulation around blood capillaries (arrow heads). A fibrillary network is formed around damaged muscle fibers (long arrow). (H\&E, X 400)

Figures 23-27: Ultrastructure of the myocardium of the fetuses maternally-treated with MSG.

Fig.23 : Atrophied cardiac muscle fibers (arrows), separated by wide spaces, with loss of striations as well as mitochondria. X 4500 


\section{Aleya Ahmed Sakr}
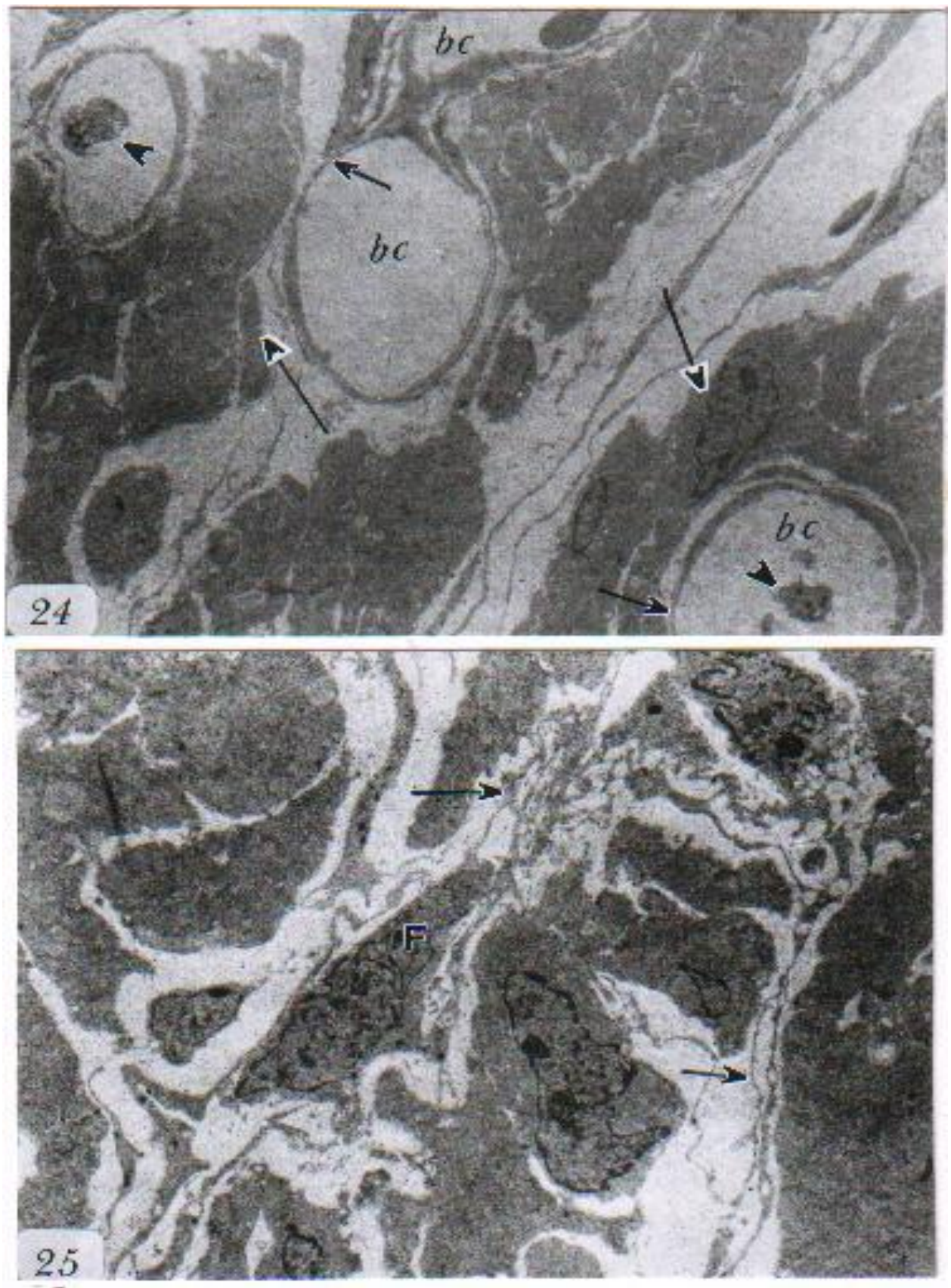

Fig. 24: Numerous blood capillaries (bc) are seen in the myocardium and destructed muscle fibers (long arrows) tend to accumulate around blood capillaries which have attenuated endothelial lining (arrows). Small macrophages are seen in the lumen of the blood capillaries (arrow heads). X 2250

Fig. 25: Fibroblasts (F) and fibrillary network (arrows) are seen between the destructed cardiac muscles. X 4500 


\section{Light and electron microscopic studies on lung........}
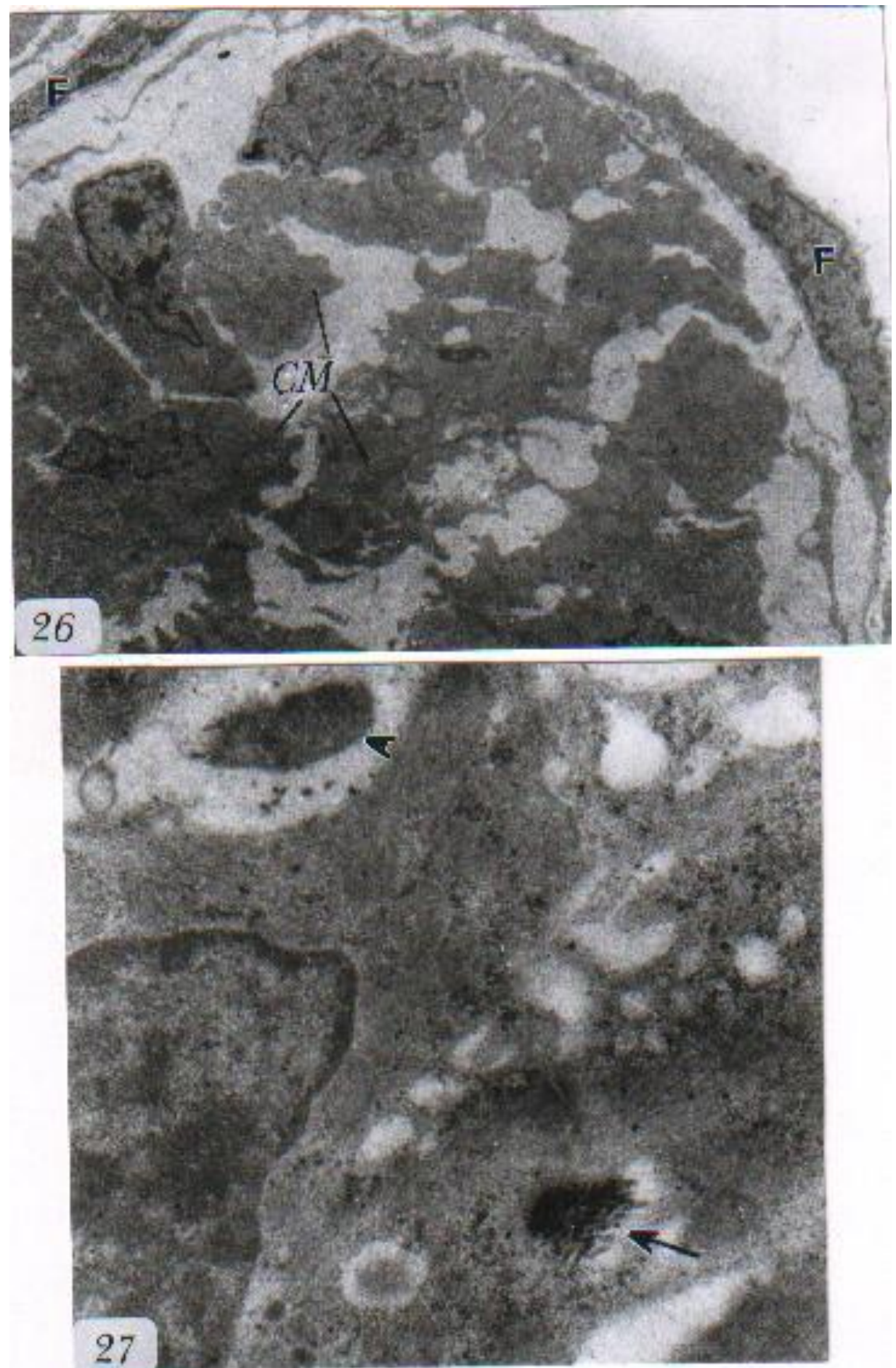

Fig. 26: Fibroblasts (F) encircle group of destructed cardiac muscles. X 4500

Fig. 27: Collagen deposition is seen inside the cardiocyte (arrow) and outside it (arrow head). X 15000 

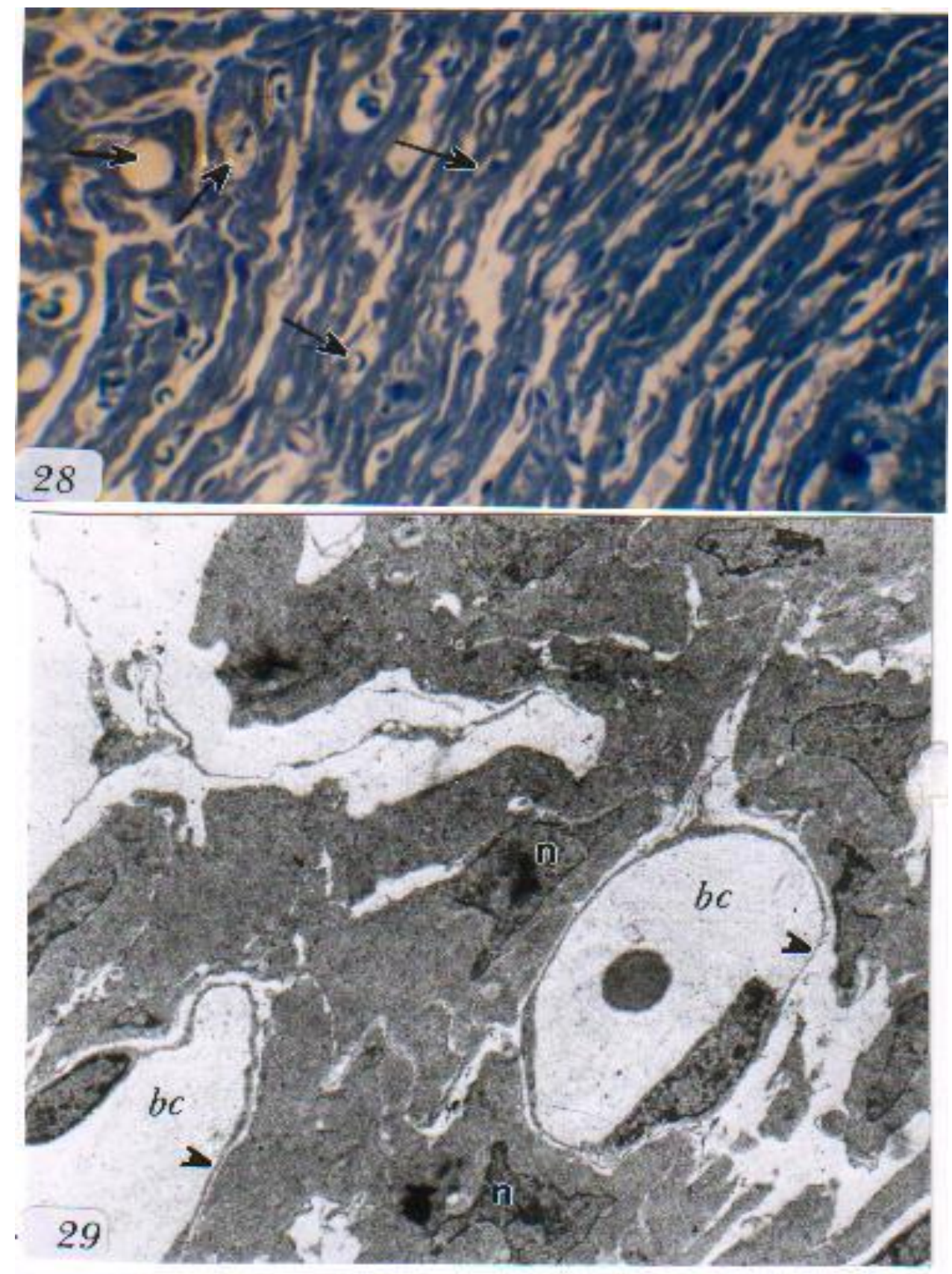

Fig. 28: Light microscopic photograph of myocardium of fetus maternally-treated with vit $\mathrm{E}$ and MSG showing severely atrophied cardiac muscles and abundance of blood capillaries (arrows). (H\&E, X 400)

Figures 29-31: Ultrastructure of the myocardium of fetuses maternally-treated with vit $\mathrm{E}$ and MSG

Fig. 29: A group of atrophied cardiac muscle fibers located mainly around blood capillaries (bc) which have attenuated endothelial lining (arrow heads). The cardiocytes nuclei (n) are irregular. X 2250 

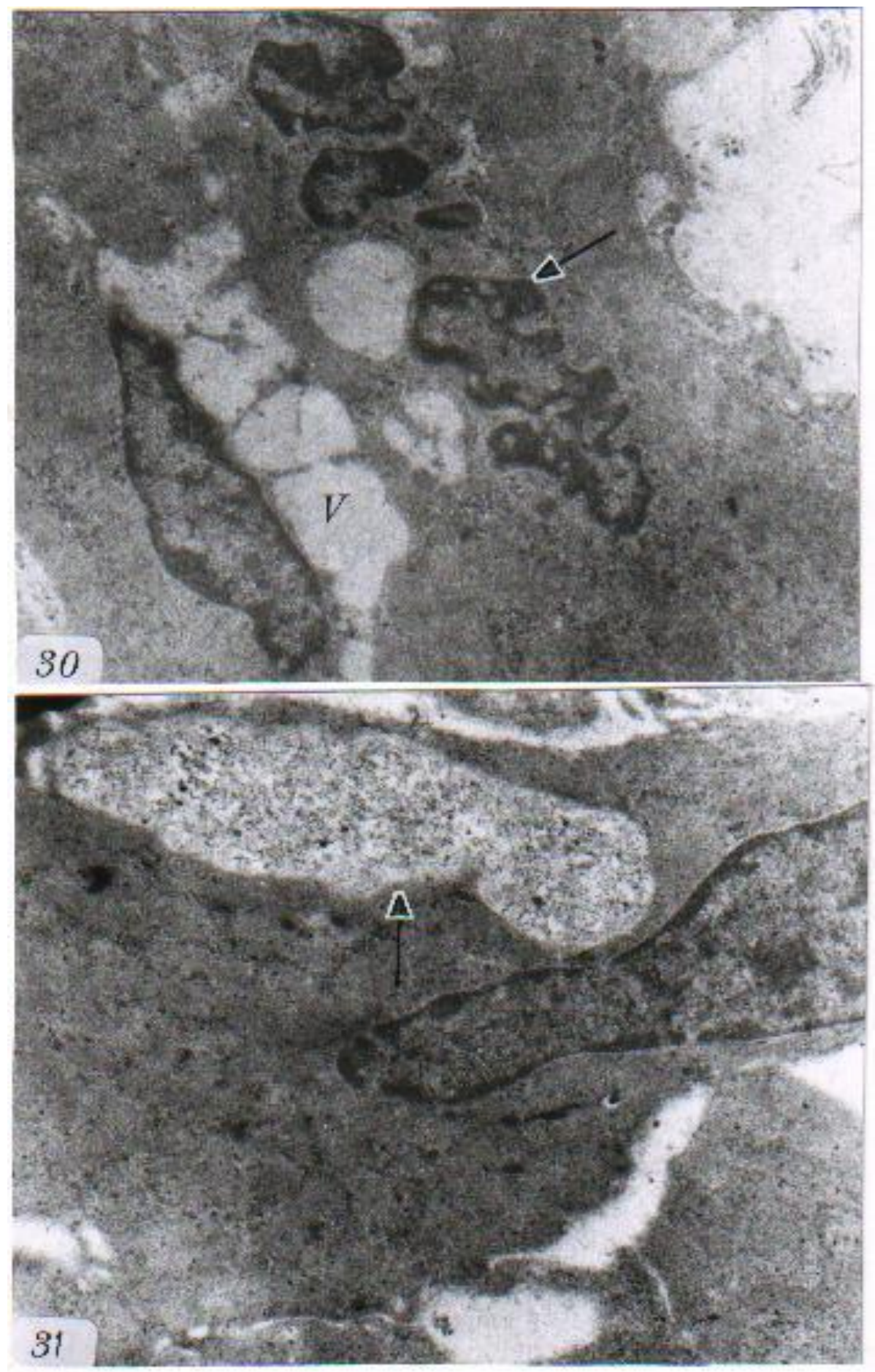

Fig. 30: Cardiac muscle fibers containing numerous vacuoles (V). Severely irregular nucleus (arrow) appears separated into several lobes. The chromatin is partially condensed along the nuclear membrane. X 9000

Fig. 31: A cardiocyte containing large electron-lucent area with flocculent and particulate contents (arrow). X 9000 


\section{Aleya Ahmed Sakr}

\section{Discussion}

The results of the present study revealed a remarkable toxic effect of monosodium glutamate on the fetal lung. The first observable change was the hypertrophy of the epithelial cells lining the bronchioles which might be distended by mucus. This increase of mucus and the hypertrophy of mucus secreting cells represent an important cause of airflow obstruction, decreased alveolar ventilation or hypoxia and consequently asthma. This observation might explain the state of asthma which was reported by many authors either in adult or newborn following MSG treatment (Allen et al., 1987; Woessner et al., 1999 and Stevenson, 2000). These authors recognized MSG as provoker of acute severe asthma and they attributed asthma to an increased airway responsiveness to an inflammatory reaction provoked by diverse stimuli. They added that, in asthma, the mast cells release mediators including histamine, bradykinin and prostaglandins and these substances are responsible for mucus secretions. Cokugras et al. (2001). attributed the increase in mucus production to either cell metaplasia or goblet cell hyperplasia.

$\mathrm{Yu}$ et al. (1997) found that MSG penetrates placental barrier and distributes almost evenly among embryonic tissues, so it is expected that it induced fetal effects similar to that exerted on adults.

In the current study, type I pneumocytes showed hypertrophy, vacuolation, and necrosis. Type II pneumocytes also showed signs of damage, but with a lesser degree than type I cells. These cells showed degenerated cytoplasmic organelles and desquamated cells were seen in the alveolar space. Ultrastructural changes in rat pneumocytes were reported by Yildrim et al. (2004) following brain trauma. As MSG caused brain trauma in mice fetuses (Yu et al., 1997)), so this might be directly responsible for the present pneumocytes damage. These authors attributed this traumatic damage to the excessive activation of glutamate receptors and overloading of intracellular $\mathrm{Ca}^{2+}$ induced by MSG which ultimately leading to neuronal death and brain trauma.

Histopathological studies revealed that when the alveolar epithelium is exposed to certain toxic agents, particularly if there is extensive destruction of type I pneumocytes, type II pneumocytes increase in number; since it is believed that some type II cells act as precursor stem cells for type I pneumocytes (Stevens and lowe, 1992). Accordingly the moderate increase in number of type II pneumocytes in the alveolar tissue of MSG maternally-treated fetuses may be considered as a sign of repair of the destroyed necrotic type I cells.

Different signs of injury were observed in the endothelial cells lining the lung blood capillaries. Monosodium glutamate-induced vascular endothelial damage was reported by Tsou et al. (2004) in porcine aortic endothelial cells cultivated in vitro. Rubin (1995) attriputed the endothelial cell damage to the direct effect of the circulating toxins or to the release of vasoactive cytokines from macrophages and platelets or from the release of lysosomal enzymes. Increase of lipid peroxidation following MSG treatment (Tsou et al., 2004) may be another factor that caused endothelial cell damage where the increase in lipid peroxidation leads to loss of membrane integrity, and cell degeneration (Rubin, 1995).

As seen in this study, a pronounced increase of collagen was observed in the alveolar wall. Tissue injury is followed by a complex set of interrelated cellular and humoral reactions that remove or neutralize injurious agents, eliminate the damaged tissue, and promote healing. Most of these reactions occur in the connective tissues and most healing ultimately depends on the deposition of collagen (Cotran et al.,1994).

In the fetuses maternally treated with vitamin $\mathrm{E}$ and $\mathrm{MSG}$, the alveolar interstitium was patchy infiltrated with 
some neutrophils. This increase of neutrophils may be one of the possible mechanisms responsible for the present alveolar damage. Jones et al. (1995) reported that the neutrophils may injure lung tissue through either proteolytic enzymes (neutrophil intracellular granules contain elastase and collagenase, which can degrade and destroy lung alveolar cells) and reactive $\mathrm{O}_{2}$ intermediates. After neutrophil activation, membrane associated NADPH oxidase converts $\left(\mathrm{O}_{2}\right)$ to the superoxide anion $\left(\mathrm{O}_{2}^{-}\right)$which is finally converted to the extremely toxic hydroxyl radical $(\mathrm{OH})$ which attacks a wide range of biologic molecules. An increase in blood neutrophils following MSG treatment was observed by Hirscu et al. (1997) in mice neonates. In addition, these authors observed that MSG also enhanced the phagocytic activity of neutrophils which was tested in vitro through the number of bacteria engulfed by the neutrophils. Unexpectedly, neutrophils were hardly encountered in fetuses maternally-treated with MSG but their number increase in fetuses maternallytreated with vit E together with MSG. So, vit $\mathrm{E}$ might enhance the appearance of the neutrophils.

It is known that MSG induced oxidative stress by lowering the activities of antioxidant enzymes like superoxide dismutase, catalase and glutathione metabolizing enzymes like glutathione reductase and glutathione peroxidase (Singh and Ahluwalia, 2003). These enzymes represent defense mechanisms against oxidative stress in the body. On the other hand, vit E contributes to defense against oxidative stress and cellular damage and it exerts protective effect for the lungs in infants suffering from bronchopulmonary dysplasia (Oski, 1980). The present data also proved that vit $\mathrm{E}$ is an effective protecting agent against pulmonary injury where type I and II penumocytes showed less damage and type II pneumocytes showed moderate increase of their lamellar contents. It also reduced the severe damage which was observed in the alveolar septal cells, but the presence of vit $\mathrm{E}$ did not result in a return of the lung cells to a state equivalent to that of the control fetuses.
Few studies have been performed on the relationship between MSG and heart. These studies had focused on the effect of MSG on the heart rate. So, the present study was done to describe the ultrastructural changes induced in the fetal myocardium as a result of maternal treatment with MSG. The most remarkable effect was the severe atrophy of the cardiac muscle fibers. Moreover, macrophages, fibroblasts and a network of fibers were evident in various areas of the myocardium. These fibers appeared to encircle groups of destructed cardiac muscle fibers of variable numbers. Abundance of blood capillaries was also observed in the myocardium of the fetuses maternally treated with MSG.

Myocardial cells have no significant regenerative capacity, so myocardial necrosis, from whatever cause, heals by formation of granulation tissue (abundant fibroblasts, macrophages and blood capillaries) which was obviously seen in the fetal myocardium of the present study. Formation of granulation tissue is a regulated process that involves a number of events, including the growth of new capillaries and fibrogenesis. On the other hand, macrophages are thought to be responsible for mediating fibrosis. They express several genes that encode for mediators such as fibronectin and plateletderived growth factor that recruit and stimulate fibroblasts to divide. On the other hand, macrophages produce angiogenesis factors that are responsible for endothelial proliferation. So, it might be responsible for the abundance of blood capillaries in the myocardium of the present fetuses (Rubin, 1995).

In the present study, the endothelial lining of the cardiac blood capillaries was markedly attenuated. The data of Vanhoutte (1989) provide evidence that MSG treated rats have altered nitric oxide (NO) production. Nitric oxide is a powerful vasodilator in the mammalian organisms and mediates several central and peripheral endocrine processes (Grossman, 1994 and Bugajski et al., 1997). Vanhoutte (1989) suggested that some of the cardiovascular changes in rats treated with MSG may be 


\section{Aleya Ahmed Sakr}

due to abnormal formation of the NO system.

Dvorak and Monahan-Earley (1988) reported that, decreased alveolar ventilation (as seen in the lung of MSG maternally treated fetuses) leads to hypoxia and hypercapnia. It is also known that hypoxia diminishes mitochondrial function and diminished ATPase and hence diminished energy dependent sodium pump with the result that sodium accumulates intracellulary with increased influx of $\mathrm{Ca}^{++}$and diffusion of potassium out of the cell. The increase of cytosolic $\mathrm{Ca}^{++}$might be responsible, in some part, on the observed myocardial damage and muscle atrophy as it leads to phospholipid degradation of the cell membranes (Cotran et al., 1994) as well as mitochondrial membranes and consequently loss of mitochondria which was noted in the fetal myocardium.

Although vitamin $\mathrm{E}$ was able to reduce the structural damage which was seen in its absence in the fetal lung, it did not exert apparent protection for the fetal myocardium and the response was very weak. This is in accordance with the results of Breed et al. (1980) who failed to find out any protective effect for vit $\mathrm{E}$ on the heart of rabbit treated with adriamycin.

The mechanism by which MSG induced cardiac or pulmonary damage is not clear. It is known that L-glutamate causes rapid membrane depolarization associated with an increase in intracellular fluids and a depletion of cell energy reserves and that depolarization continues until glutamate is removed from the extracellular milieu (Rascher, 1981). This may lead to a condition in which the cells are ultimately excited to death. Three other possible explanations for these results should be considered and it might lead to MSGinduced cell damage: 1) The first possibility is the genetic factor, such as variation in cellular response to cytotoxicity and the fetal cells may be particularly sensitive to glutamate; 2) The fetal blood capillaries may be highly permeable to the glutamate which allow rapid diffusion of glutamate from the blood to the tissues; 3 ) The third possibility is the phagocytosis and enzyme release by macrophages.

\section{References}

1. Allen, D.H.; Delohery, J. and Barker, G. (1987): Monosodium L. glutamate-induced asthma. J. Allergy Clin. Immunol., 80 (4) : $530-537$.

2. Bellisle, E. (1998): Effects of monosodium glutamate on human food palatability. Ann. NY. Acad. Sci., 855 : 438 - 441 .

3. Breed, J.G.; Zimmerman, A.N.; Dormans, J.A. and Pinedo, H.M. (1980): Failure of the antioxidant vit $\mathrm{E}$ to protect against adriiamyyycin induced cardiotoxicity in the rabbit. Cancer Res., $40: 2033$ 2038.

4. Bugajski, J.; Borycz, J.; GadekMichalska, A.; Glod, R. and Bugaiski, A.J. (1997) : Mediation by nitric oxide of the carbachol - induced corticosterone secretion in rats. J. Physiol. Pharmacol., 48 : $277-284$

5. Cokugras, H.; Akcaxaya, N.; Seckin, Y.; Camciogln, Y.; Sarimurat, N. and Aksoy, F. (2001) : Ultrastructural examination of bronchial biopsy specimens from children with moderate asthma. Thorax, $56: 25-29$

6. Cotran, R.S.; Kumar, V. and Robbins, S.L. (1994) : Cellular Injury and Cellular Death. In : Robbin's. Pathologic Basis Diseases. $5^{\text {th }}$ edition. Philadelphia, London, Toronto, Montreal, Sydney, Tokyo : Saunders WB company.

7. Dolnikoff M.S.; Kater, C.E.; Egami, M.; de Andrade, I.S. and Marmo, M. (1988) : Neonatal treatment with monosodium glutamate increases plasma corticosterone in the rat. Neuroendocrinology, 48 (6) : 645 649.

8. Dvorak, A.V. and Monahan-Earley (1988) : Diagnostic ultrastructural pathology. CRC press, Boca Raton, Ann Arbor, London, Tokyo.

9. Frieder, B. and Grimm, V.E. (1984): Prenatal monosodium glutamate (MSG) treatment given through the mother's diet causes behavioral deficits in rat offspring. Int. J Neurosci; 23 (2) : 117 - 126.

10. Gill, S.S.; Mueller, R.W.; McGuire, P.F. and Pulido, O.M. (2000): Potential target sites in peripheral tissues for excitatory neurotransmission and excitotoxicity. Toxicol. Pathol., 28 (2) : 277-284.

11. Gonzalez-Burgos, I., Perez-Vega, M.I. and Beas-Zarate, C. (2001) : Neonatal exposure to monosodium glutamate induces cell death and dendritic hypotrophy in rat prefrontocortical pyramidal neurons. Neurosci ., 1297 (2) : 69 - 72 . 
12. Grossman, A. (1994) : No news is good news. Endocrinology, 134 : 1003 - 1005.

13. Hirscu, M.; Saulea, G.; Vidrassu, N. and Baciu, I. (1997) : Effect of monosodium glutamate on blood neutrophils phagocytic activity and phagocytic response in mice. Rom. J. Physiol., 34 (1) : 95 - 101.

14. Horio, T. (2000) : Effect of various taste stimuli on heart rate in humans. Chem. Senses, 25 (2) : 149 - 153.

15. Jones, R.; Reid, L.M.; Zapol, W.M.; Tomashefski, J.; Kirton, O. and Kobayashi, K. (1995) : Pulmonary vascular pathology. Human and experimental studies. In : Zapol WM, Falke. KJ, eds. Acute respiratory failure. New York : Marcel Dekker.

16. Mistlberger, R. E. and Antle, M. C.(1999) : Neonatal monosodium glutamate alters circadian organization of feeding, anticipatory activity and photic masking in the rat. Brain Res., 842 : 73 83.

17. McCord, J.M. and Fridovich, I. (1978) : The biology and pathology of oxygen radicals. Ann. Intern. Med., 89 : 122 - 127.

18. Natta, C.; Machlin, L. and Brin, M. (1980) : A decrease irreversibly sickled erythrocytes in sickle cell anemia patients given vitamen E. Am. J. Clin. Nutr., 33 : $968-971$.

19. Oski. F.A. (1980) : Vitamen E. A radical defense. J. Med., 303 (8) : 454-455.

20. Rascher, K. (1981) : Monosodium glutamate-induced lesions in the rat cingulate cortex. Cell tissue Res., 220 : 239 -250 .

21. Rubin, E. (1995) : Essential pathology. $3^{\text {rd }}$ Ed. Lippincott. Williams and Wilkins, Philadelphia.

22. Schoelch, C.; Hubschle, T.; Schmidt, I. and Nuesslein-Hildesheim, B. (2002) : MSG lesions decrease body mass of suckling-age rats by attenuating circadian decreases of energy expenditure. Am. J.
Physiol. Endocrinol. Metab., 283 (3) : 604 $-611$.

23. Singh, K. and Ahluwalia, P. (2003) : Studies on the effect of monosodium glutamate (MSG) administration on some antioxidant enzymes in the arterial tissue of adult male mice. J. Nutr. Sci. Vitaminol., 94 (2) : $145-148$.

24. Stevens, A. and Lowe, J. S. (1992) : Histology-Gower Medical Publishing. London and New York.

25. Stevenson, D.D. (2000) : Monosodium glutamate and asthma. J. Nutr., $130: 1067$ -1073 .

26. Tokarev, D. and Jezova, D. (2000) : Effect of nitric oxide inhibition on blood pressure and corticosterone responses in adult rats neonatally treated with glutamate. Physiol. Res., 49 : 87 - 94.

27. Tsou, T.C.; Yeh, S.C.; Tsai, F.Y. and change, L. W. (2004) : The protective role of intracellular GSH status in the arseniteinduced vascular endothelial dysfunction. Chem. Res. Toxicol. , 17 (2) : $208-217$.

28. Vanhoutte, P.M. (1989) : Endothelium and control of vascular function. Hypertension, $13: 658-667$.

29. Woessner, K. M.; Simon, R.A. and Stevenson, D. (1999) : Monosodium glutamate sensitivity in asthma. J. Allergy Clin. Immunol., 104 (2 pt1) : 305 - 310.

30. Yildirim, E.; kaptanoglu, E.; Ozisik, K.; Beskonakli, E.; Okutan, O.; Sargon, M.F.; Kiline, K., and Sakinci, U. (2004) : Ultrastructural changes in pneumocyte type II cells following transmatic brain injury in rats. Eur. J. Cardiothorac. Surg., 25 (4) : $523-529$.

31. Yu, T.; Zhao, Y.; Shi, W.; Ma, R, and Yu, L. (1997) : Effects of maternal oral administration of monosodium glutamate at a late stage of pregnancy on developing mouse fetal brain. Brain Res., 747 (2) : 195 $-206$. 


\section{دراسة بالميكرسكوب الضوئي و الاليكترونى لرئة وعضلات قلب أجنة

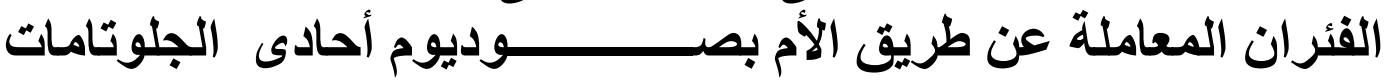 ودور فيتامين إى ضـاد السمية}

\section{عليه أحمد صقر}

قسم علم الحيو ان - كلية العلوم - جامعة عين شمس علر

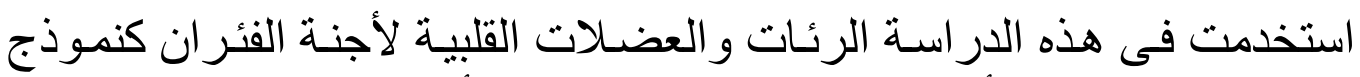

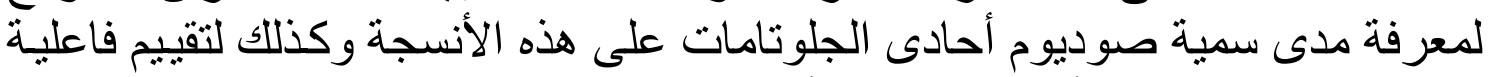

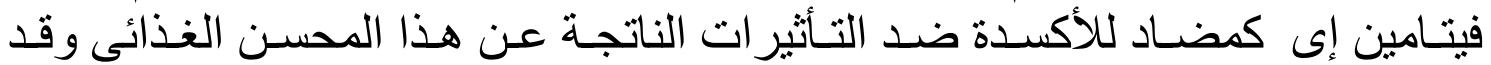

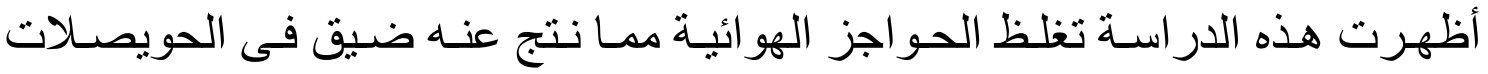

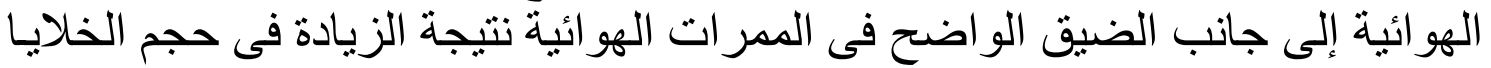

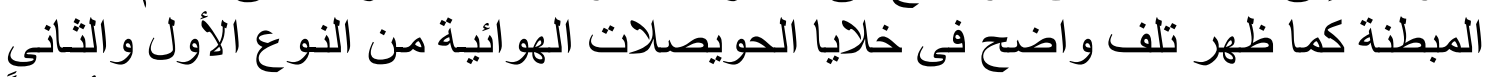

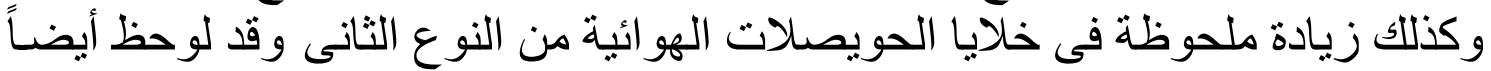

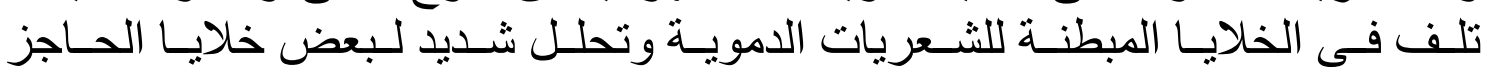

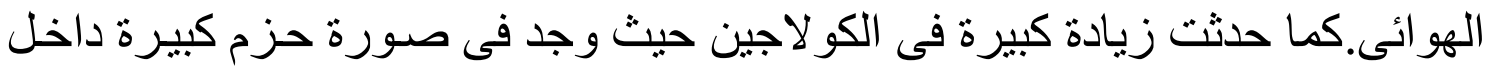

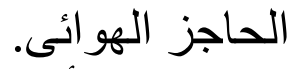

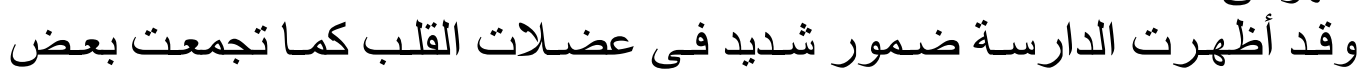

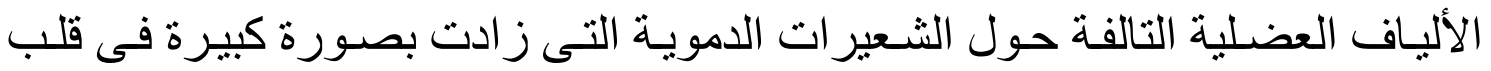

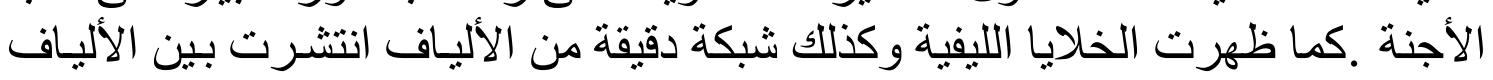
العضلية التالفة أو حولها.

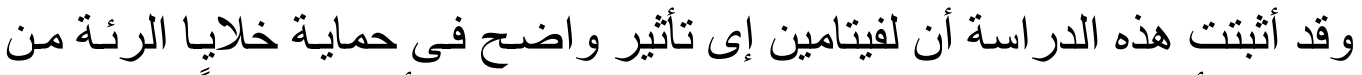

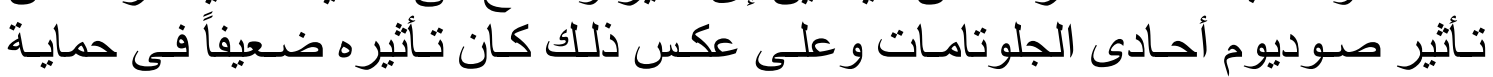

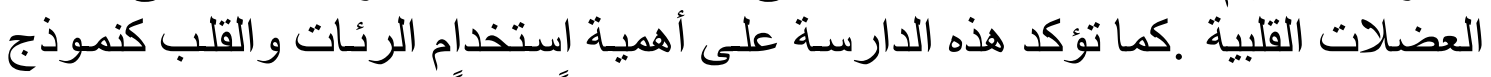
لدر اسة فاعلية العقار ات المختلفة و التى لم تلقى اهتماماً شديداً خاصة في مجال التئ دارسات

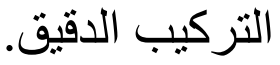

